\title{
Pectolinarigenin inhibits cell viability, migration and invasion and induces apoptosis via a ROS-mitochondrial apoptotic pathway in melanoma cells
}

\author{
YUANLE DENG $^{1}$, QIANYU ZHANG $^{1}$, YALI LI ${ }^{1}$, LIQUN WANG ${ }^{1}$, SHUPING YANG ${ }^{2}$, \\ XIAOTONG CHEN $^{1}$, CAILIN GAN ${ }^{2}$, FANG HE ${ }^{1}$, TINGHONG YE ${ }^{2}$ and WENYA YIN ${ }^{1}$ \\ ${ }^{1}$ Department of Nutrition, Food Safety and Toxicology, West China School of Public Health and \\ Healthy Food Evaluation Research Center; ${ }^{2}$ State Key of Laboratory of Biotherapy and Cancer Center, \\ West China Hospital, Sichuan University, Chengdu, Sichuan 610064, P.R China
}

Received September 16, 2019; Accepted May 13, 2020

DOI: 10.3892/ol.2020.11977

\begin{abstract}
Pectolinarigenin a plant secondary metabolite that has various biological effects, including the inhibition of melanogenesis and tumor growth. Melanoma has a high degree of malignancy, with rapid metastasis and severe drug resistance, explaining the need for new candidate drugs that inhibit tumor growth and metastasis. However, the pharmacological action and mechanism of pectolinarigenin on the growth and metastasis of melanoma remain elusive. Thus, the present study aimed to investigate the role of pectolinarigenin in melanoma cell proliferation, apoptosis, migration and invasion. Apoptotic and metastasis-associated proteins were analyzed using western blotting. The results demonstrated that pectolinarigenin treatment resulted in growth inhibition and apoptosis induction in melanoma cells, arising from the loss of mitochondrial transmembrane potential, reactive oxygen species and the altered expression of apoptosis-associated proteins. In addition, wound-healing and Transwell assays demonstrated the potential of pectolinarigenin to impair the migration and invasion of melanoma cells in accordance with the changes in the expression of the associated proteins. Therefore, the results of the present study suggested that pectolinarigenin may serve a pivotal role in promoting melanoma cell apoptosis and reducing metastasis, and may thus be a promising potential candidate for an anti-melanoma treatment strategy.
\end{abstract}

Correspondence to: Professor Wenya Yin, Department of Nutrition, Food Safety and Toxicology, West China School of Public Health and Healthy Food Evaluation Research Center, Sichuan University, 16 Section 3 of Renmin South Road, Wuhou, Chengdu, Sichuan 610064, P.R. China

E-mail: yinwenya@scu.edu.cn

Key words: pectolinarigenin, melanoma cell, apoptosis, migration, invasion

\section{Introduction}

The latest report by the World Health Organization revealed that there were 288,000 new cases of melanoma and 61,000 deaths from melanoma in 2018 worldwide (1). A study by the American Cancer Society revealed that melanoma ranked as the fifth most prevalent cancer among men and the sixth among women, with a gradually growing incidence over the past years, whereas the incidence of most solid cancers has tended to drop or stabilize $(2,3)$. Melanoma, which accounts for $\sim 70 \%$ of skin cancer deaths, is the most lethal type of skin cancer, characterized by rapid deterioration, early metastasis and high mortality, and derives from the pigment-producing melanocytes $(2,4)$. Melanin, a natural pigment that is produced by a specialized group of cells known as melanocytes and by melanoma cells, can affect the behavior of melanoma cells or their surrounding environment, and abnormal melanocyte proliferation can develop into melanomas (5). Melanogenesis is subject to complex regulatory control by multiple agents, involving pathways that are activated by receptor-dependent and receptor-independent mechanisms in hormonal, auto-, para- or intracrine manners, and is a metabolic pathway characteristic for melanocytes, in which L-tyrosine is transformed to heterogenous melanin biopolymer through a series of oxidoreduction reactions (6-9).

Lee et al (10) have demonstrated the inhibitory effect of pectolinarigenin on melanogenesis. In addition, induction of melanogenesis in melanoma cells is associated with increases of nuclear hypoxia-inducible factor $1 \alpha$ (HIF1- $\alpha$ ) expression accompanied by the upregulation of multiple HIF-1-dependent genes involved in the regulation of glucose metabolism, angiogenesis and stress responses, which suggests that melanogenesis serves a key role in the regulation of cell metabolism (11). In addition, the presence of melanin pigment or active melanogenesis attenuates the sensitivity and efficacy of chemo-, radio- or immunotherapy in patients with melanoma; thus, the inhibition of melanogenesis may sensitize melanoma cells and improve the outcome of radiotherapy in patients with melanoma $(12,13)$. Since pectolinarigenin inhibits melanogenesis, it may be an effective approach for anti-melanogenesis treatment (10). 
Melanin is produced by melanocytes and melanoma cells, and can transform melanocytes to proliferate abnormally and develop into melanomas. Therefore, it was hypothesized in the present study that melanogenesis may attenuate the cytotoxic effect of pectolinarigenin on melanoma cells, and inhibition of melanogenesis may sensitize melanoma cells (11-13). This suggests that treatment with pectolinarigenin may be considered as an alternative, physiologically based approach for the treatment of melanoma.

However, the exact biological action of pectolinarigenin on melanoma cells and its underlying mechanisms have not been reported in detail. The present study aimed to evaluate the potential effects of pectolinarigenin on melanoma cell proliferation and migration and invasion in vitro, as well as its underlying molecular mechanisms. Previous studies have reported that $30 \mu \mathrm{M}$ pectolinarigenin treatment suppressed melanin biosynthesis without cytotoxicity in melan-a cells (10), whereas when treated with $20 \mu \mathrm{M}$ pectolinarigenin for $48 \mathrm{~h}$, the viability of bone marrow macrophages was not influenced (14), and $\geq 100 \mu \mathrm{M}$ pectolinarigenin did not affect the proliferation of skin fibroblasts $142 \mathrm{BR}$, the $\mathrm{IC}_{50}$ of which was $>100 \mu \mathrm{M}$ pectolinarigenin (15). Thus, the present study proposed that within the $40 \mu \mathrm{M}$ range of concentration, pectolinarigenin may be safe for normal cells. In the present study, we investigated the role of pectolinarigenin in cell proliferation, cell apoptosis, and cell migration and invasion in melanoma cancer cells to provide a new agent for an ant-melanoma strategy.

\section{Materials and methods}

Chemicals and reagents. Pectolinarigenin, with a purity $>98 \%$ as measured by HPLC, was purchased from Sichuan Weikeqi Biological Technology Co., Ltd. 3-(4,5-Dimethylthiazol2-yl)-2,5-diphenyltetrazoliumbromide (MTT), dimethyl sulfoxide (DMSO), rhodamine 123 (Rh123) and 2',7'-dichlorodihydrofluorescein diacetate (DCFH-DA) were purchased from Sigma-Aldrich; Merck KGaA. Hoechst 33258 and the Annexin V-FITC and propidium iodide (PI) apoptosis detection kit were purchased from Nanjing KeyGen Biotech Co., Ltd. For western blotting experiments, the primary antibodies against matrix metalloproteinase-9 (MMP9, cat. no. 13667T), matrix metalloproteinase-2 (MMP2, cat. no. 4022s), TIMP2 (cat. no. 5738S), Bax (cat. no. 2772S), Bcl2 (cat. no. 4223S), Cleaved Caspase-3 (cat. no. 9661S), Stat3 (cat. no. 9139S), phosphorylated (p)-Stat $3^{\text {Tyr705 }}$ (cat. no. 7145T) and $\beta$-actin (cat. no. 3700T) were purchased from Cell Signaling Technology, Inc., and the secondary antibodies were obtained from OriGene Technologies, Inc. For in vitro assays, pectolinarigenin was prepared as a $40 \mathrm{mM}$ stock solution in DMSO and stored at $-20^{\circ} \mathrm{C}$. The stock solution was diluted with the relevant medium for subsequent applications.

Cell lines and culture. Non-pigmented human melanoma cell lines A375 and CHL-1, the former of which is recalcitrant and exhibits high malignancy, and mouse pigmented melanoma cells with high metastatic potential B16-F10 (B16) were selected for the present study based on their origin, malignant degree and metastatic ability. The three cell lines were obtained from the American Type Culture Collection. The A375 and CHL-1 cells were cultured in DMEM (Hyclone;
Cyvita), and the B16-F10 cells were cultured in RPMI-1640 medium (Hyclone; Cyvita), and both mediums were supplemented with $10 \%$ heat-inactivated fetal bovine serum (FBS, Gibco; Thermo Fisher Scientific, Inc.) and $1 \%$ penicillin and streptomycin. All cells were incubated at $37^{\circ} \mathrm{C}$ in a humidified atmosphere of $5 \% \mathrm{CO}_{2}$.

Cell viability assay. The viability of pectolinarigenin-treated melanoma cells was determined by an MTT colorimetric assay. A375, B16 and CHL-1 cells in the logarithmic phase were seeded into 96 -well plates at $2-4 \times 10^{3}$ cells in $100 \mu 1$ per well for adherence, followed by the addition of pectolinarigenin diluted in culture medium corresponding to each cell line in a final volume of $100 \mu \mathrm{l}$ and a final concentration of $0,2.5,5,10,20$ or $40 \mu \mathrm{M}$. The cells were then cultured in a $37^{\circ} \mathrm{C} \mathrm{CO}_{2}$ incubator for 24,48 and $72 \mathrm{~h}$. Subsequently, $20 \mu \mathrm{l} 5 \mathrm{mg} / \mathrm{ml}$ MTT solution was added into each well and incubated for an additional $2-4 \mathrm{~h}$ at $37^{\circ} \mathrm{C}$. The liquid phase was discarded, and the purple-colored formazan precipitates were solubilized by the addition of $150 \mu 1$ DMSO to each well. The viability of melanoma cells was assessed by a Spectra MAX M5 microplate spectrophotometer (Molecular Devices, LLC) at $570 \mathrm{~nm}$.

Colony formation assay. A colony formation assay was used to determine the effects of pectolinarigenin on the colony formation rate of melanoma cells. A375, B16 and CHL-1 cells were seeded in 6-well plates at 500-800 cells per well. At $24 \mathrm{~h}$, the supernatants were replaced with fresh media containing the indicated doses $(0,2.5,5,10,20$ or $40 \mu \mathrm{M})$ of pectolinarigenin, and the plates were cultured for 10-15 days in a $37^{\circ} \mathrm{C} \mathrm{CO}_{2}$ incubator. Subsequently, the cells were washed with PBS, followed by fixing with $100 \%$ methanol and staining with a $0.5 \%$ crystal violet solution in the room temperature for $\sim 15 \mathrm{~min}$, after which the colonies ( $>50$ cells) were counted using light microscopy (Olympus Corp.).

Morphological analysis of cell nuclei by Hoechst 33258 staining. Cell shrinkage, chromatin condensation and apoptotic bodies, which are typical morphologic features of apoptotic cells, were used to evaluate cell apoptosis as previously described (16). Briefly, A375 and B16 cells were seeded onto $18-\mathrm{mm}$ coverslips in a 6 -well plate at density of $3-8 \times 10^{4}$ per well and incubated in $37^{\circ} \mathrm{C}$ overnight. After the cells were seeded on the coverslips, the groups treated with various concentrations $(0-40 \mu \mathrm{M})$ of pectolinarigenin for $48 \mathrm{~h}$ were washed with ice-cold PBS twice and fixed in ice-cold $100 \%$ methanol for $\sim 15 \mathrm{~min}$. The cells were stained with the Hoechst 33258 solution, and images were captured under a Leica DM4000B fluorescence microscope (Leica Microsystems, Inc.) to observe the nuclear morphology and identify the apoptotic bodies.

Apoptosis assay by flow cytometry (FCM). Flow cytometry was utilized to test apoptosis using an Annexin V-FITC/PI apoptosis detection kit according to the manufacturer's instructions. Briefly, A375 and B16 melanoma cells were treated with different doses of pectolinarigenin (0-40 $\mu \mathrm{M})$ for $48 \mathrm{~h}$, harvested and washed twice with ice-cold PBS, followed by the addition of Annexin V-FITC and PI in the dark for 5 min 
in the room temperature. The apoptotic state in each group was analyzed by FCM (FACSCalibur; BD Biosciences), and Flow Jo software version 7.6.1 (Treestar) was used to analyze the data and determine the average apoptotic rates of three independent experiments.

Detection of mitochondrial membrane potential ( $\Delta \Psi m)$. Mitochondrial membrane potential was detected by FCM using Rh123 staining. A375 and B16 cells, exposed to a range of concentrations of pectolinarigenin $(0-40 \mu \mathrm{M})$ for $48 \mathrm{~h}$, were collected, washed and incubated with $10 \mu \mathrm{M}$ Rh123 for $30 \mathrm{~min}$ at $37^{\circ} \mathrm{C}$ in the dark. Following the incubation, the cells were washed twice with cold PBS, and the fluorescence was subsequently detected by dyeing of Rh123 and FCM (as aforementioned and detected using the FITC channel). The mean values of triplicate experiment results were calculated.

Detection of reactive oxygen species (ROS). ROS was detected by DCFH-DA, which is hydrolyzed by intracellular esterases to produce a non-fluorescent DCFH product that can be oxidized by ROS and other oxidizing species to produce a highly fluorescent DCF product. A375 $\left(5 \times 10^{4}\right.$ per well) and B16 $\left(5 \times 10^{4}\right.$ per well $)$ cells were treated with $0-40 \mu \mathrm{M}$ pectolinarigenin for $48 \mathrm{~h}$, collected, washed and incubated with $10 \mu \mathrm{M}$ (DCFH-DA) for $30 \mathrm{~min}$ at $37^{\circ} \mathrm{C}$ in the dark. Following the incubation, the cells were washed twice with ice-cold PBS, and the fluorescence was subsequently assessed by FCM. This experiment was repeated three times.

Migration assay. Cell migratory ability was measured using a modified wound healing assay. The cells were cultured in 6 -well plates until they reached $80 \%$ confluence. A sterile $10 \mu \mathrm{l}$ plastic pipette tip was used to create a wound in each well, followed by washing with PBS. Fresh medium containing $2 \%$ FBS and pectolinarigenin $(0,10,20$ or $40 \mu \mathrm{M})$ was added to the well. After $48-\mathrm{h}$ incubation at $37^{\circ} \mathrm{C}$ with $5 \% \mathrm{CO}_{2}$, the cells that migrated into the wounded area were photographed under a light microscope and the cells within the area were counted manually. The assay was performed three times.

Transwell migration and invasion assays. A Boyden chamber (8- $\mu \mathrm{m}$ pore size) migration assay was conducted as previously described, with several modifications (16). Briefly, $1.0 \times 10^{5}$ A375 or B16 cells suspended in $100 \mu \mathrm{l}$ serum-free medium were added into the upper chamber of a 24-well Transwell insert, and $600 \mu \mathrm{l}$ culture medium (DMEM for A375 and 1640 for B16) with $10 \%$ FBS was put into the lower chamber. In addition, pectolinarigenin $(0,10,20$ or $40 \mu \mathrm{M})$ was added into both chambers. The cells were incubated at $37^{\circ}$ for $48 \mathrm{~h}$, and the migrated cells that were attached to the lower surface of the Transwell membrane were fixed in $100 \%$ methanol and stained with $0.5 \%$ crystal violet at room temperature for $15 \mathrm{~min}$. The non-migrated cells on the upper surface of the membrane were removed by cotton swabs. Images of migrated cells in three randomly selected fields were captured and evaluated under a light microscope.

The invasion assay was performed according to methods outlined in previous studies (17). Briefly, $60 \mu$ l diluted Matrigel (BD Biosciences) was placed in the upper chamber of a 24-well Transwell plate and incubated at $37^{\circ} \mathrm{C}$ for polymerization. The lower chamber was filled with $600 \mu 1$ medium (DMEM for A375 and 1640 for B16) containing 10\% FBS. Cells (A375 or $\mathrm{B} 16)\left(1.0 \times 10^{5}\right)$ in $100 \mu \mathrm{l}$ serum-free medium were added into the upper chamber and treated with pectolinarigenin $(0,10,20$ or $40 \mu \mathrm{M})$. Following $48-\mathrm{h}$ incubation at $37^{\circ} \mathrm{C}$, the rest of the invasion assay was conducted using the same protocol as the migration assay. Invading cells in three areas per well were counted, and the inhibition rate of invasion was calculated. The two assays were performed three times.

Western blot analysis. A375 and B16 cells ( $2 \times 10^{5}$ cells) were seeded in petri dishes and treated with pectolinarigenin $(0,10$, 20 or $40 \mu \mathrm{M}$ ) for $48 \mathrm{~h}$ at $37^{\circ} \mathrm{C}$. The cells were lysed in ice-cold RIPA buffer (Beyotime Institute of Biotechnology) (containing protease inhibitor cocktail and phosphalase inhibitor cocktail) for $30 \mathrm{~min}$ on the ice after washing twice with PBS. Protein lysates were centrifuged at $12,000 \mathrm{x}$ g for $15 \mathrm{~min}$ at $4^{\circ} \mathrm{C}$ to collect the supernatant of the lysate. Protein concentrations were determined by the BCA Protein Assay Kit (Pierce; Thermo Fisher Scientific, Inc.) using known amounts of bovine serum albumin (Beyotime Institute of Biotechnology) to standardize and equalize the protein concentration before loading onto gels. Protein lysates (50 $\mu \mathrm{g}$ per lane) were resolved by electrophoresis on 10 or $12 \%$ SDS polyacrylamide gels and transferred onto PVDF membranes (Amersham; Cytiva). The membranes were blocked with $5 \%$ skim milk in Tris-buffered saline containing 1\% Tween 20 (TBST; pH 7.4) at room temperature for $1 \mathrm{~h}$, and incubated overnight at $4^{\circ} \mathrm{C}$ with primary antibodies. After washing five times with TBST at room temperature, the membranes were incubated with a 1:2,000 dilution of the relevant HRP-conjugated secondary antibody for $2 \mathrm{~h}$ at room temperature, followed by five washes with TBST. The blots were developed using an enhanced chemiluminescence (ECL) kit (Amersham; Cytiva). A monoclonal $\beta$-actin antibody was used as an internal control. ImagePro Plus v6.0 (Media Cybernetics) was used for densitometry analysis, and normalized against $\beta$-actin expression. Original images of the blots may be viewed in Supplementary Figure 1.

Statistical analysis. The data are expressed as the mean \pm SD of at least three independent experiments. The differences between the groups were examined by one-way ANOVA followed by Dunnett's post hoc test using SPSS v16.0 software (SPSS, Inc.). Excel 2016 software (Microsoft Corporation) was used to process the figures. $\mathrm{P}<0.05$ was considered to indicate a statistically significant difference.

\section{Results}

Pectolinarigenin inhibits melanoma cell viability. The chemical structure, molecular weight and molecular formula of pectolinarigenin, a yellow powder composed of flavonoids, are presented in Fig. 1A. First, cell viability was examined using a wide range of pectolinarigenin concentrations in melanoma cells A375, B16 and CHL-1 to analyze the toxic or protective function of pectolinarigenin in the present study. The results demonstrated that pectolinarigenin treatment reduced the viability of A375, B16 and CHL-1 cells compared with the untreated control groups, and the effects appeared stronger 
A<smiles>COc1ccc(-c2cc(=O)c3c(O)c(O)c(O)cc3o2)cc1</smiles>

B
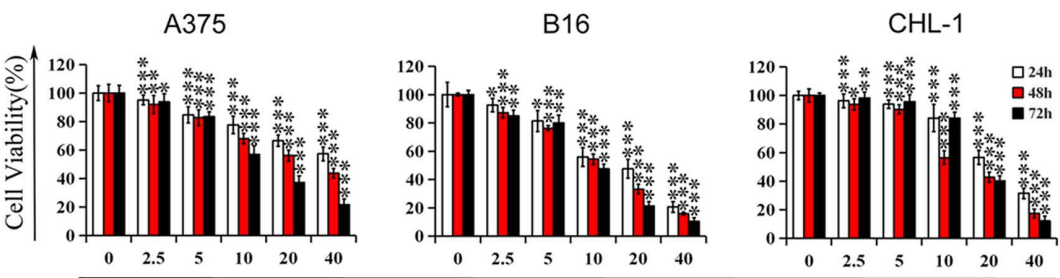

Pectolinarigenin( $\mu \mathrm{M} / \mathrm{L})$

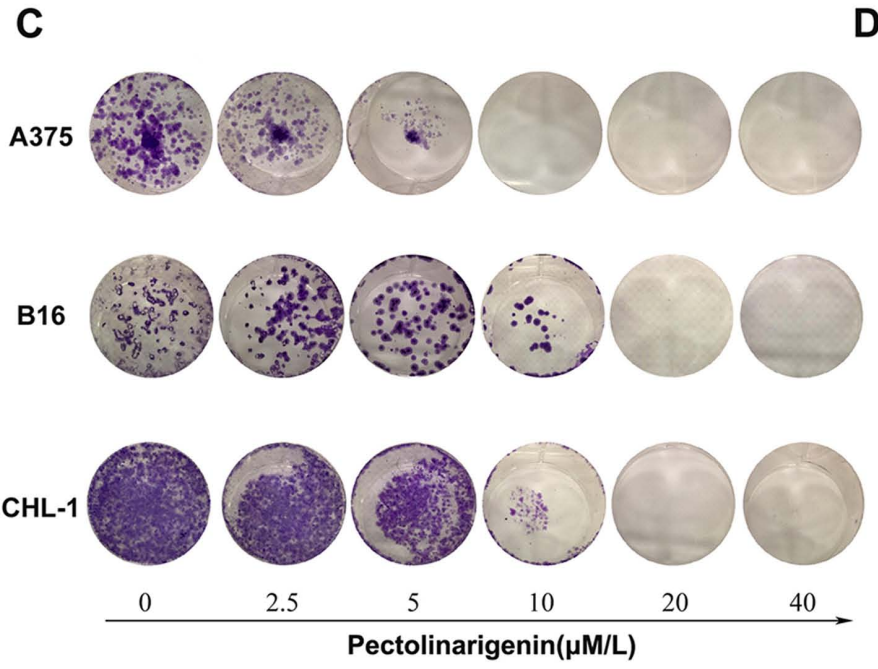

D
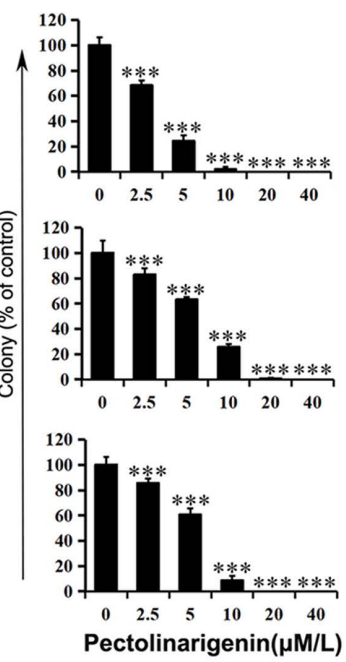

Figure 1. Inhibitory effects of pectolinarigenin on melanoma cell viability and colony formation. (A) Chemical structure of Pectolinarigenin. (B) Melanoma cells (A375, B16 and CHL-1) were treated with pectolinarigenin for 24, 48 and $72 \mathrm{~h}$, and cell viability was tested by an MTT assay. (C) Effects of pectolinarigenin on colony formation in melanoma cell lines A375, B16 and CHL-1. (D) Statistical analyses of the inhibition in the colony formation assays are presented as the percentage of surviving colonies relative to the untreated control group. Data are presented as the mean \pm SD of at least three independent experiments. ${ }^{*} \mathrm{P}<0.05,{ }^{* *} \mathrm{P}<0.01$ and ${ }^{* * *} \mathrm{P}<0.001$ vs. $0 \mu \mathrm{M}$ pectolinarigenin.

with higher concentrations (Fig. 1B). Following 48-h exposure to $40 \mu \mathrm{M}$ pectolinarigenin, the viability of the $\mathrm{A} 375, \mathrm{~B} 16$ and CHL-1 cells was reduced to $43.79,15.94$ and $34.76 \%$ of that in the control groups, respectively.

To validate the MTT assay results, a colony formation assay was performed to detect the proliferation of melanoma cells following continuous exposure to pectolinarigenin. The results demonstrated that long-term treatment resulted in a decrease in the colony formation of A375, B16 and CHL-1 cells (Fig. 1C and D). More specifically, pectolinarigenin exerted an inhibitory effect on colony number and, with no visible colony formation observed in the high concentration groups (20 and $40 \mu \mathrm{M}$ ). These results demonstrated that pectolinarigenin inhibited the viability and proliferation in A375, B16 and CHL-1 cells.

Pectolinarigenin induces apoptosis in melanoma cells. Hoechst 33258 staining assay was performed to initially assess the effects of pectolinarigenin on the induction of apoptosis in A375 and B16 cells. Upon exposure to pectolinarigenin for $48 \mathrm{~h}$, nuclear fragmentation and apoptotic bodies in the treated groups were observed in the A375 and
B16 cells (Fig. 2A). In addition, the higher the pectolinarigenin concentration used, the more notable the apoptotic hallmarks the lower number of living cells, thus confirming that pectolinarigenin induced apoptosis in melanoma cells.

To quantify the apoptotic rates induced by pectolinarigenin, an Annexin V-FITC/PI assay was performed and analyzed by FCM. The results demonstrated that pectolinarigenin induced apoptosis in both A375 and B16 cells after treatment with the indicated concentration of pectolinarigenin for $48 \mathrm{~h}$ (Fig. 2B and C). Treatment with $40 \mu \mathrm{M}$ pectolinarigenin led to an increase of the apoptotic rate by $>6$-fold in A375 cells and 10-fold in B16 cells compared with the respective untreated control groups. Thus, pectolinarigenin induced apoptosis in A375 and B16 cells.

The expression levels of apoptosis-associated proteins Bcl2, Bax and Cleaved Caspase-3 were determined by western blotting. As presented in Fig. 2D, in A375 cells, pectolinarigenin treatment reduced the levels of $\mathrm{Bcl} 2$ expression, whereas those of pro-apoptotic proteins Bax and Cleaved Caspase-3 were increased compared with the untreated control group. In B16 cells, pectolinarigenin treatment downregulated the expression of the anti-apoptotic $\mathrm{Bcl} 2$ and upregulated the 


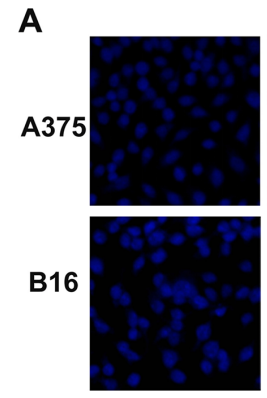

0
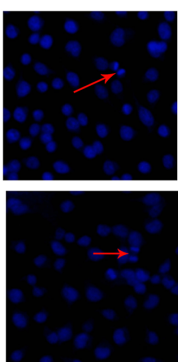

2.5
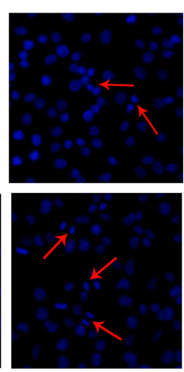

5

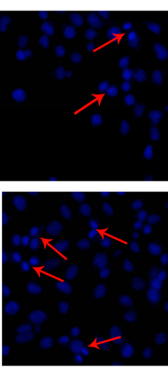

10
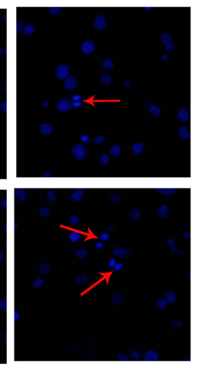

20

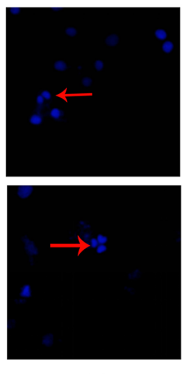

40

Pectolinarigenin $(\mu \mathrm{M})$

A375 Pectolinarigenin $(\mu \mathrm{M})$

B

$\overline{\mathbf{n}}$

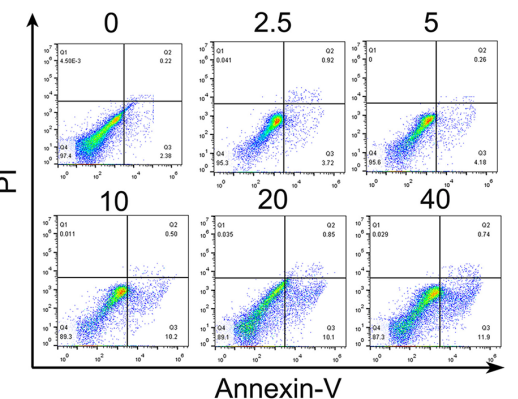

C

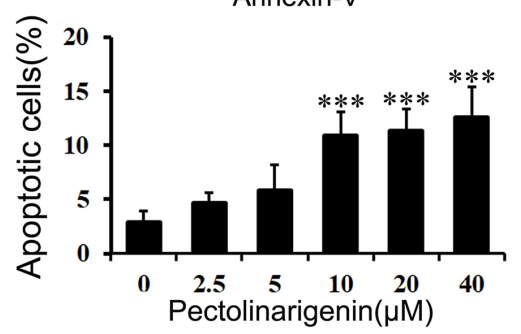

D

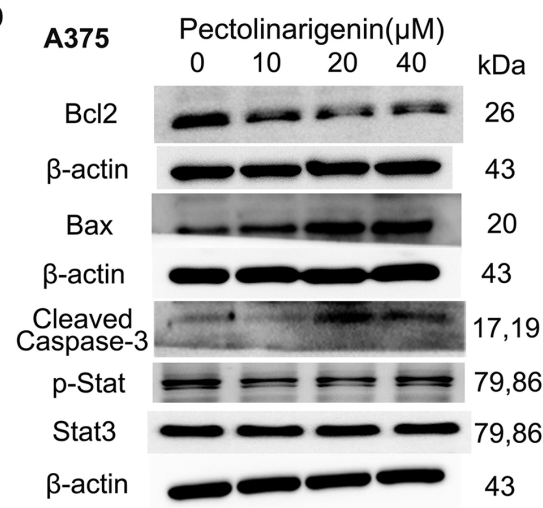

E

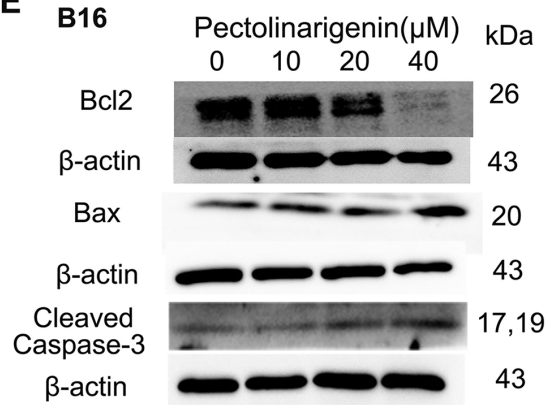

B16 Pectolinarigenin $(\mu \mathrm{M})$
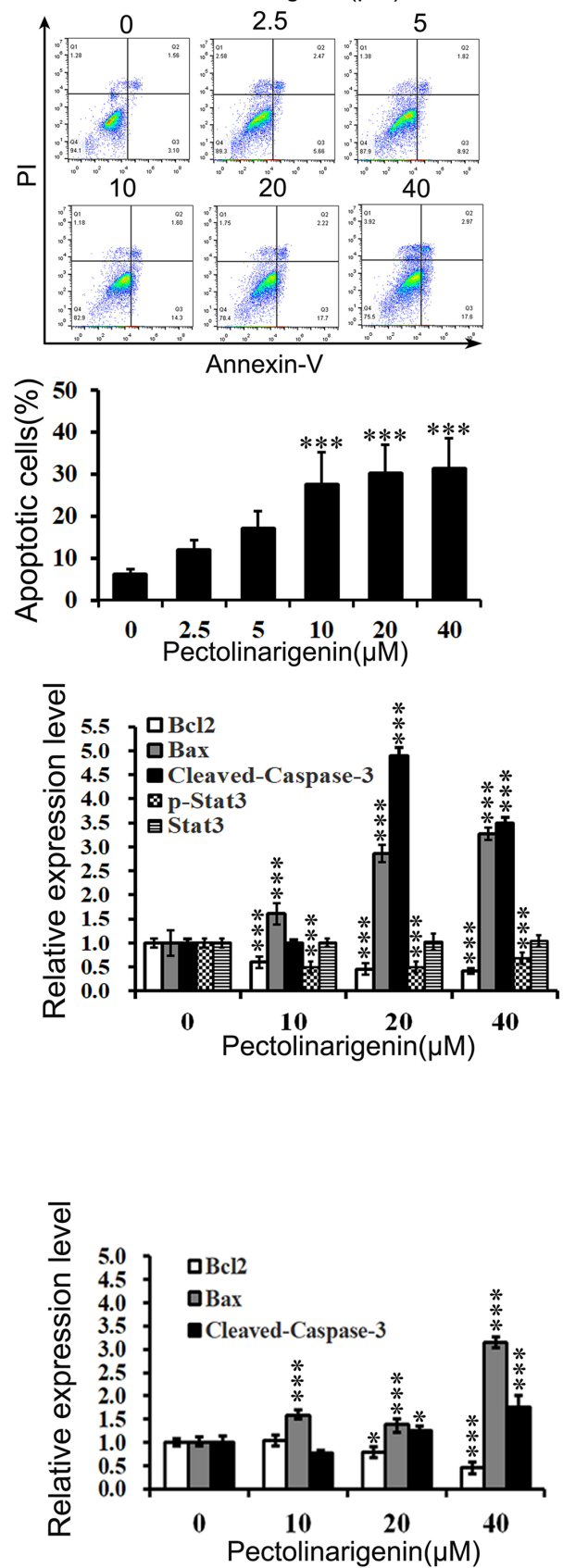

Figure 2. Pectolinarigenin induces apoptosis in A375 and B16 cells. (A) A375 and B16 cells stained with Hoechst 33258 were observed under fluorescence microscopy (x20 magnification). Red arrows indicate bright blue regions, which represent the apoptotic bodies. (B and C) The cells were exposed to the indicated concentrations of pectolinarigenin for $48 \mathrm{~h}$. Apoptosis was assessed by a flow cytometric Annexin V/PI labeling assay. (D and E) Effects of pectolinarigenin on the expression levels of apoptosis-associated proteins in A375 and B16 cells were determined by western blotting. The protein band and the loading control that follows were from the different parts of the same gel, and the loading controls and protein bands were grouped together in the figure from different gels. Data are presented as the mean $\pm \mathrm{SD}$ of at least three independent experiments. ${ }^{*} \mathrm{P}<0.05$ and ${ }^{* * * *} \mathrm{P}<0.001$ vs. $0 \mu \mathrm{M}$ pectolinarigenin. PI, propidium iodide. 
expression of pro-apoptotic Bax and Cleaved Caspase-3; however, the loss of $\mathrm{Bcl} 2$ accumulation when $\mathrm{B} 16$ cells were treated with the higher concentrations of pectolinarigenin may have been affected by the different period of dose-response curve (lag period and log period) (Fig. 2E). Thus, the higher concentrations of pectolinarigenin induced more loss of $\mathrm{Bcl} 2$ in B16 cells.

Effects of pectolinarigenin on $\Delta \Psi m$ and ROS. To further test whether apoptosis induced by pectolinarigenin was associated with the mitochondrial apoptotic pathway, $\Delta \Psi \mathrm{m}$ and intracellular ROS levels were measured. After 48-h pectolinarigenin treatment, loss of $\Delta \Psi \mathrm{m}$ (except for the 2.5 and $5 \mu \mathrm{M}$ in B16) compared with that in the untreated controls was observed in both A375 and B16 cells (Fig. 3A and B), and the balance of cellular ROS levels in the two cell types was visibly disturbed (Fig. 3C and D), that the changes of ROS levels in the two cells varied significantly compared with the control group $(\mathrm{P}<0.05)$. With the increasing of concentration, ROS level may increase or decrease unsteadily. These results suggested that the mitochondria-mediated apoptotic pathway may serve an important role in pectolinarigenin-induced apoptosis in B16 and A375 cells.

Pectolinarigenin decreases the migratory and invasive abilities of A375 and B16 cells. Based on the antiproliferative and apoptosis-inducing effects of pectolinarigenin, as well as on the metastatic capability of tumor cells, which poses the predominant threat in cancer-related mortality, the present study investigated whether pectolinarigenin may affect the migration- and invasion-associated abilities of melanoma cells. Wound healing and Transwell assays were used to validate the antimetastatic effects of pectolinarigenin on A375 and B16 cells.

In the wound healing assay with A375 and B16 cells, significant reductions in cell migration were observed at $48 \mathrm{~h}$ in the groups treated with pectolinarigenin compared with that in the untreated control (Fig. 4A).

The results of the Transwell migration and invasion assays demonstrated that the numbers of cells treated with pectolinarigenin that migrated to the lower surfaces of the Transwell membranes were reduced compared with the control group cells. The migration and invasion of A375 and B16 cells were notably diminished by pectolinarigenin (Fig. 4B and C). Taken together, these results demonstrated that pectolinarigenin inhibited cell motility and invasiveness in vitro.

The expression levels of proteins MMP2, MMP9, TIMP2, Stat3, and p-Stat $3^{(\text {Tyr705) }}$, which are associated with cell migration and invasion, were determined by western blotting. The results demonstrated that the protein levels of MMP2 and MMP9 were decreased in the treated groups of B16 cells compared with those in the untreated control group (Fig. 2D and 4D). A similar result was obtained in A375 cells (Fig. 4E), where pectolinarigenin treatment also upregulated the protein expression of TIMP2 and downregulated the expression of $\mathrm{p}$-Stat3. These results demonstrated that pectolinarigenin inhibited cell migration and invasion in both A375 and B16 cells, which was associated with the downregulation of MMP2 and MMP9 and/or the alteration of TIMP2 and -Stat3.

\section{Discussion}

Melanoma is a highly malignant skin cancer with a considerable metastatic potential, drug resistance and poor treatment efficacy, as well as an increasing incidence in the last decade $(2,18)$. Thus, novel and efficient alternatives to current anti-melanoma agents are urgently needed.

Extensive studies have demonstrated that components derived from plants, which are generally considered safe, can exert potent anticancer activities (19). As a typical candidate, flavonoids have exhibited potential for cancer suppression through apoptosis induction and other different mechanisms, such as autophagy induction $(20,21)$. Pectolinarigenin is a natural extract from multiple herbal medicinal plants, including Cirsium japonicum, Eupatorium odoratum and Trollius chinensis (22). Previous studies have reported that pectolinarigenin demonstrates potent inhibitory activity on melanogenesis and effective antitumor activity in vivo and in vitro $(10,15)$.

To the best of our knowledge, there has been no study on the biological activity of pectolinarigenin in melanoma cells, and the precise role and mechanism of pectolinarigenin on melanoma needs further research. To verify the anti-melanoma effect of pectolinarigenin in this study, experiments were performed to demonstrate the inhibitory effect of pectolinarigenin on the proliferation and metastasis of melanoma cells. The results demonstrated that pectolinarigenin suppressed the viability and proliferation of melanoma cells. The next objective of the study was to explore the effects of pectolinarigenin on apoptosis and on the underlying mechanism. Apoptosis is an essential mechanism targeted by numerous anticancer agents, characterized by shrinkage of the cell and nucleus, chromatin condensation and finally the formation of apoptotic bodies $(23,24)$. Thus, inducing apoptosis is regarded as a potential strategy for cancer treatments (25). The results of the Hoechst and the Annexin V-FITC/PI assays in the present study confirmed that pectolinarigenin induced apoptosis in melanoma cells. In addition, Bcl-2 family proteins are involved in the induction of intrinsic apoptosis, with $\mathrm{Bcl} 2$ inhibiting apoptosis and Bax promoting apoptosis in various cell types, such as prostate and breast cancer cells (26). The caspase family is considered to comprise critical regulators of apoptosis initiation and execution, one of which, Caspase-3, is an important effector protease that is cleaved and activated during apoptosis (27). In the present study, pectolinarigenin treatment significantly elevated the expression of pro-apoptotic proteins Bax and Cleaved Caspase-3, whereas the expression of the anti-apoptotic protein $\mathrm{Bcl} 2$ was reduced, which suggested the occurrence of apoptosis induced by pectolinarigenin and was consistent with previous reports that demonstrated that pectolinarigenin exerted potent anti-proliferative activity in breast cancer cells by inducing apoptosis and the alteration of apoptosis-related proteins (28). A375 and B16 cells are from different origins, which may cause the differences in cell sensitivity observed in the present study. Since pectolinarigenin inhibits melanogenesis, it may be an effective approach for anti-melanogenesis treatment (10). In addition, inhibition of melanogenesis may sensitize melanoma cells and improve the efficacy of therapy (13). Flavonoid extracts from flower of Paeonia decomposita and Paeonia 


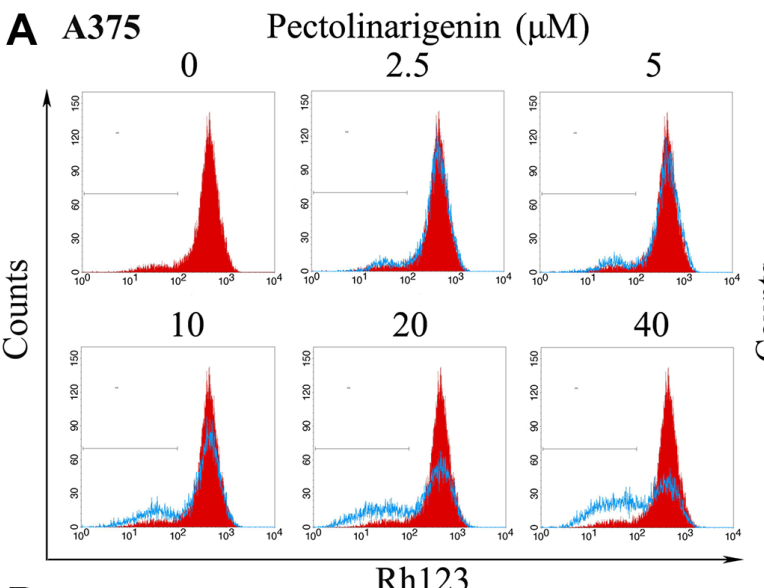

B $\mathbf{A 3 7 5}$

B16 Pectolinarigenin $(\mu \mathrm{M})$
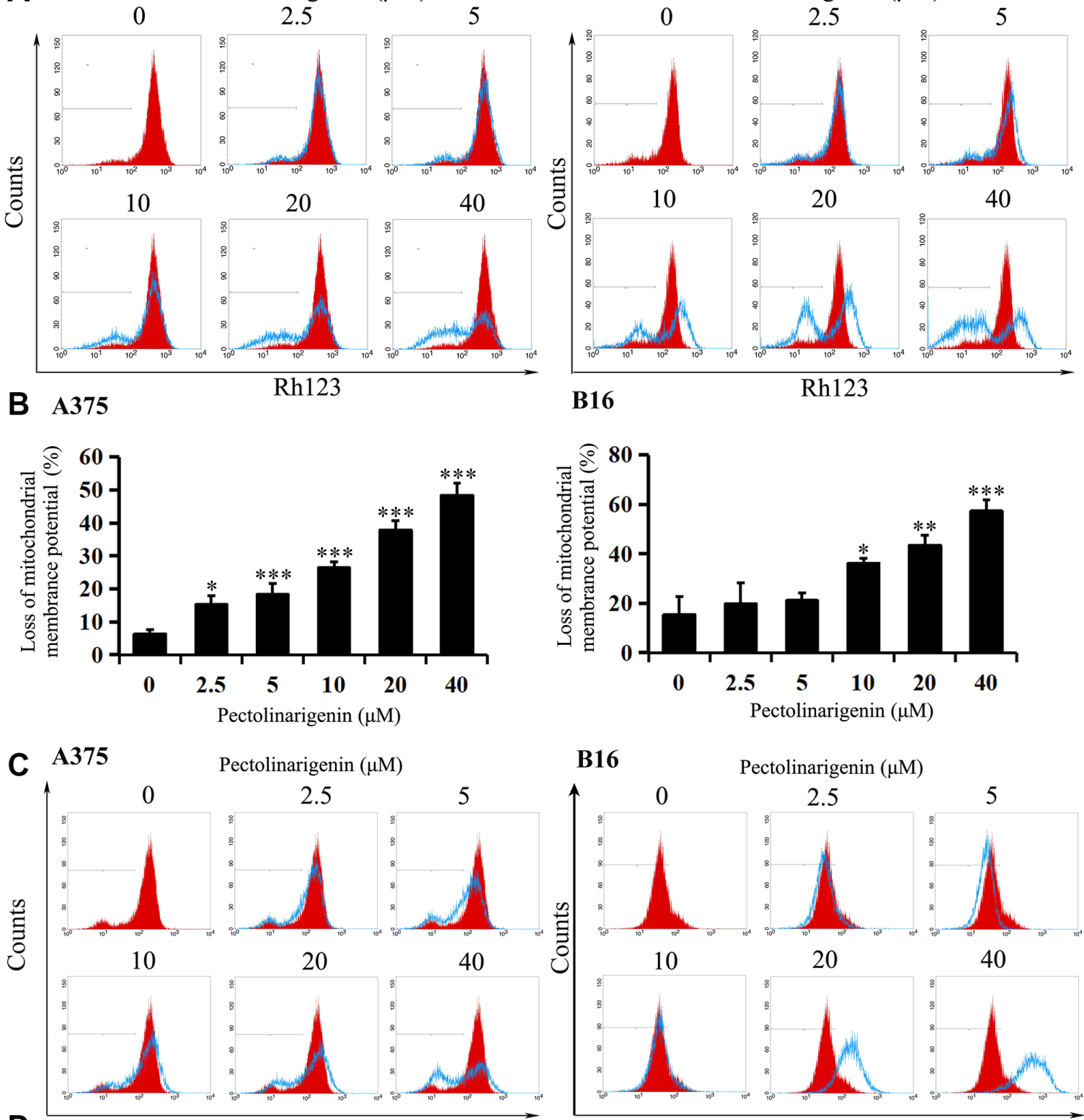

D $\mathbf{A 3 7 5}$
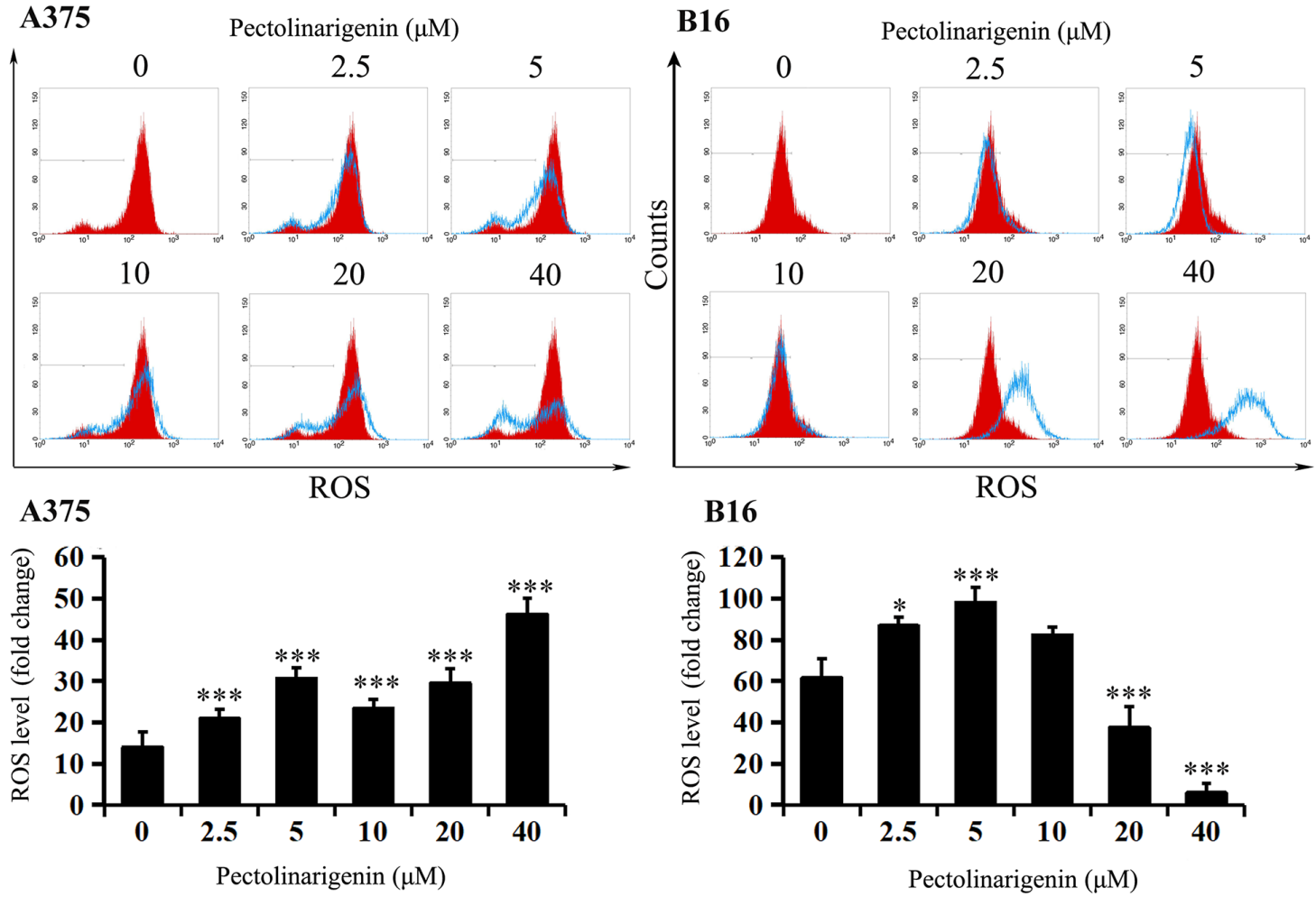

Figure 3. Changes in mitochondrial membrane potential and ROS induced by pectolinarigenin treatment in A375 and B16 cells. (A and B) A375 and B16 cells were treated with pectolinarigenin for $48 \mathrm{~h}$. The changes in mitochondrial membrane potential were determined by staining with Rh123, which was detected by flow cytometry. Red represents the control group. (C and D) A375 and B16 cells treated with various concentrations of pectolinarigenin for 48 h were incubated with DCFH-DA, and the ROS levels were analyzed by flow cytometry. Red represents the control group. The results are presented as the mean \pm SD of at least three independent experiments. ${ }^{*} \mathrm{P}<0.05,{ }^{* *} \mathrm{P}<0.01$ and ${ }^{* * *} \mathrm{P}<0.001$ vs. $0 \mu \mathrm{M}$ pectolinarigenin. ROS, reactive oxygen species; Rh123, rhodamine 123 .

ostii inhibit tyrosinase oxidase activity and downregulate the expression of melanocortin 1 receptor (MC1-R), tyrosinase and melanogenesis-related proteins (29). Pectolinarigenin, as a natural flavonoid, may enhance the inhibitory effect of MC1-R expression in B16, which is an MC1-R positive cell. Flavonoids target critical oncogenic signaling pathways and receptors, 

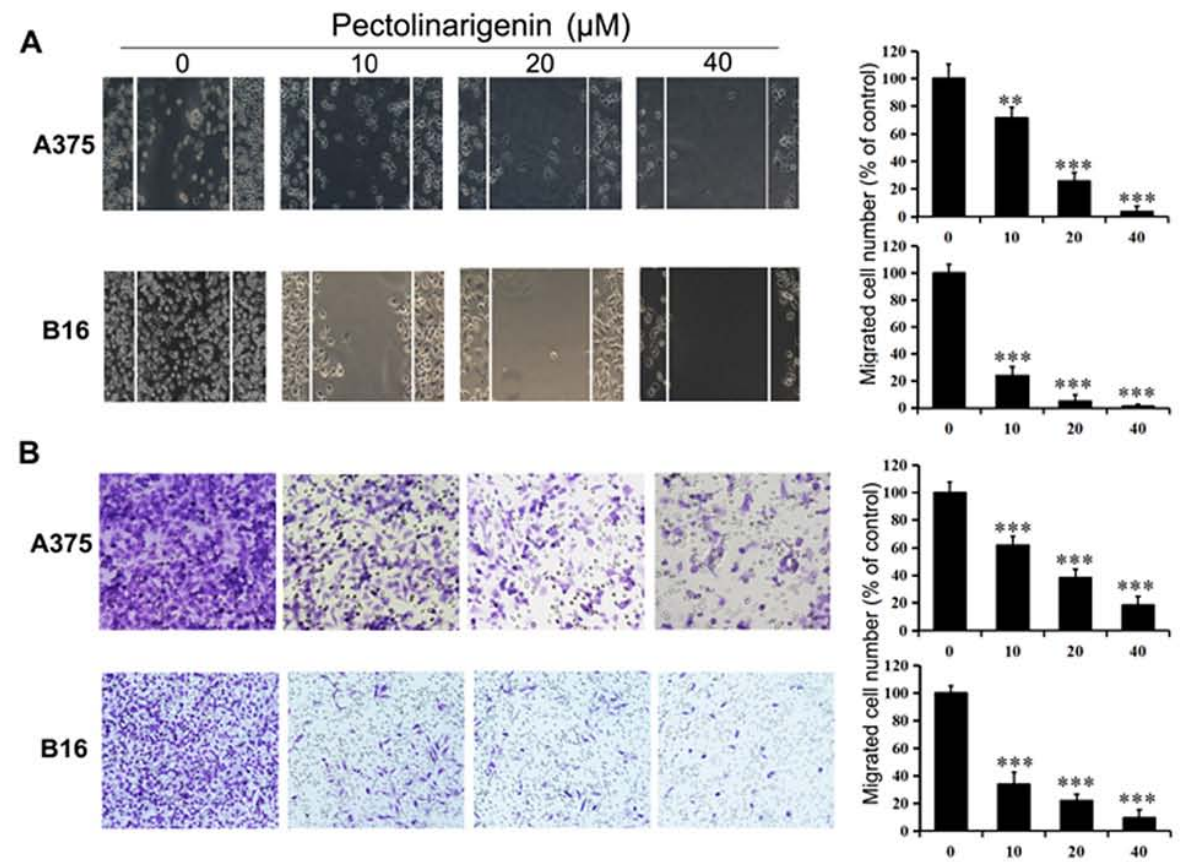

C
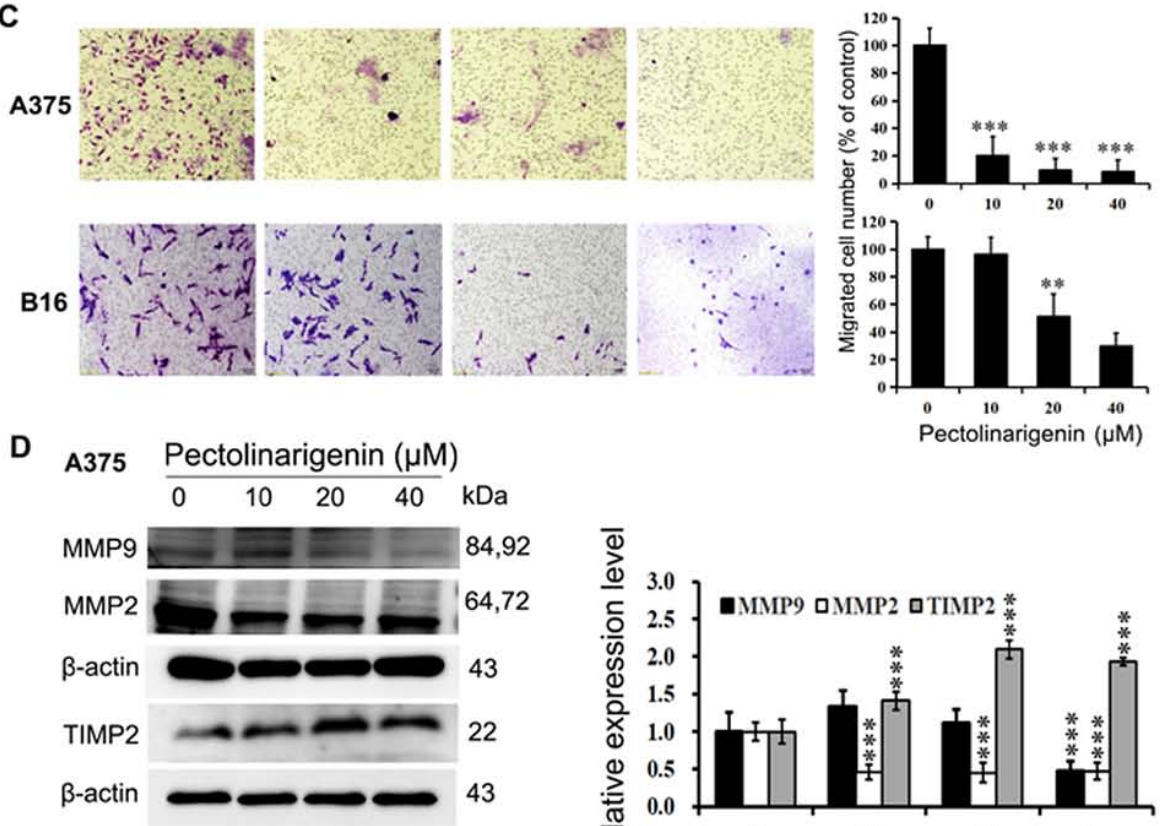

Pectolinarigenin $(\mu \mathrm{M})$
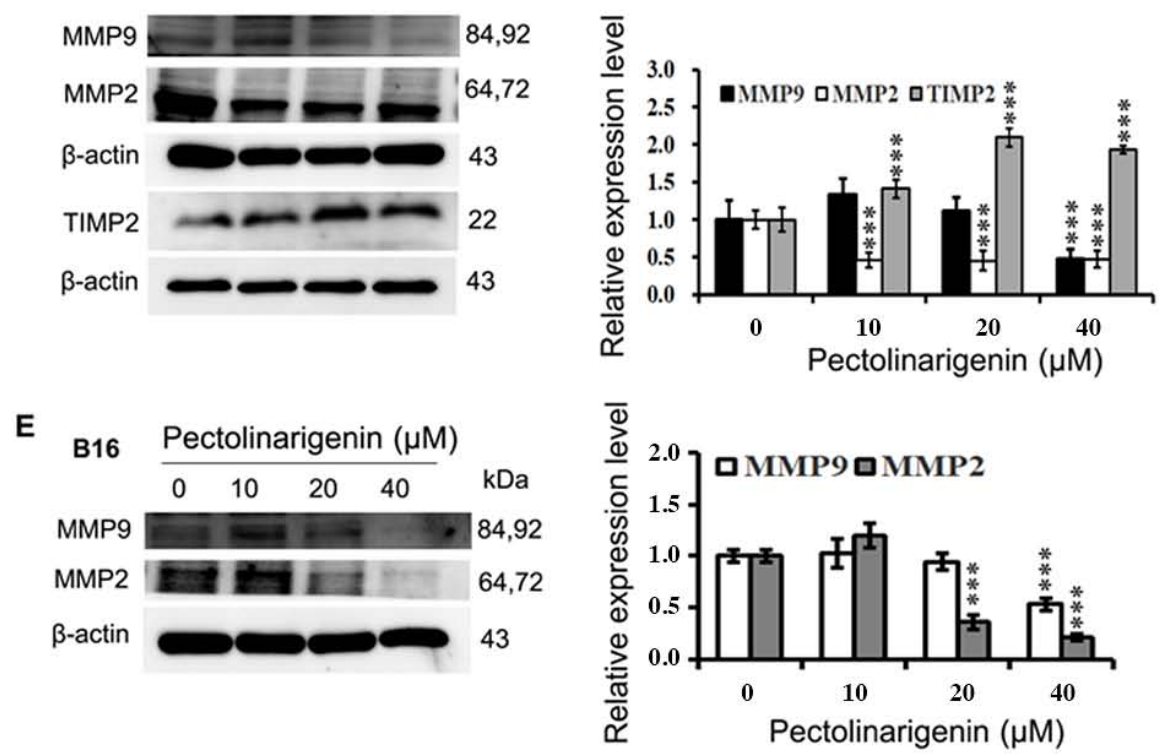

Figure 4. Pectolinarigenin decreases A375 and B16 cell migration and invasion. (A) Representative images from a light microscope (x10 magnification) of the wound healing assay using A375 and B16 cells treated with pectolinarigenin for $48 \mathrm{~h}$; The lines represent the area occupied by the initial scraping, and migrated cells were counted. (B) Transwell migration assay of A375 and B16 cells upon treatment with the indicated concentration of pectolinarigenin, after which the migrated cells were stained, photographed and quantified (x20 magnification). (C) Transwell invasion assay of A375 and B16 cells upon treatment with the indicated concentration of pectolinarigenin, after which the invading cells were stained, photographed and quantified (x20 magnification). (D and E) Expression of MMP2, MMP9, and TIMP2 were determined by western blotting with $\beta$-actin as the internal control. The protein band and the loading control that follows were from the different parts of the same gel, and the loading controls and protein bands were grouped together in the figure from different gels. Data are presented as the means $\pm \mathrm{SD}$ of at least three independent experiments. ${ }^{* * *} \mathrm{P}<0.01$ and ${ }^{* * * * *} \mathrm{P}<0.001 \mathrm{vs} .0 \mu \mathrm{M}$ pectolinarigenin. MMP, matrix metalloproteinase; TIMP2, tissue inhibitor or metalloproteinases 2; p, phosphorylated. 
such as PI3K/ATK, EGFR, MAPK (30), which may affect the sensitivity of different cell lines. Thus, subtle differences in cell sensitivity were observed in the present study.

Excessive or low levels of ROS disrupt the mitochondrial membrane potential and induce apoptosis, which is associated with a decreasing mitochondrial transmembrane potential $(31,32)$. The results of the present study demonstrated that the apoptosis induced by pectolinarigenin in melanoma cells was associated with the loss of $\Delta \Psi \mathrm{m}$ and dysregulated ROS levels. Mitochondria and ROS-generating enzymes can also be targeted by flavonoids; however, previous studies have reported that flavonoids may serve either as ROS scavengers or stimulators (30). These conflicting results may be due to the potential of all antioxidants to be converted into pro-oxidants (30). It may be speculated that certain flavonoids may require a specific dose range to act as antioxidants, whereas outside of this range, they may stimulate ROS production. In the present study, pectolinarigenin intervention affected the ROS levels in A375 and B16 in different ways. In A375 cells, pectolinarigenin served as an ROS stimulator to induce apoptosis. In B16 cells, low concentration of pectolinarigenin $(2.5$ and $5 \mu \mathrm{M})$ served as a ROS stimulator, whereas when the concentration was $>5 \mu \mathrm{M}$, pectolinarigenin exerted an antioxidant effect to decrease the ROS content. These differences between A375 and B16 cells may have occurred due to the varying sensitivities of the two cell types. The different responses to pectolinarigenin in A375 and B16 melanoma cells from different species are supported by a previous study Yang et al (33) have demonstrated that the ROS level in A375 cells treated with hinokiflavone was notably increased, whereas that in B16 cells was first increased and then decreased, and loss of $\Delta \Psi \mathrm{m}$ and unbalanced the level of ROS in both A375 and B16 cells was observed. Therefore, it is possible that the ROS-mediated mitochondrial apoptotic pathway is involved in melanoma cell death induced by pectolinarigenin.

Cancer is a complex process, and the hallmark migratory and invasive ability of cancer cells is the primary cause of cancer-associated mortality (34). Migration and invasion are prerequisites for tumor metastasis, and suppressing the metastatic capability of cancer cells is regarded as a principal strategy for cancer therapy (35). Thus, the present study conducted assays to evaluate the metastatic ability of A375 and B16 cells following exposure to pectolinarigenin. The results demonstrated that pectolinarigenin induced an inhibition of cell migration and invasion compared with those in untreated cells. In addition, the degradation of basement membranes is a key step in cellular invasion and metastasis formation. Several lines of evidence have implicated that MMPs serve a crucial role in these complex multistep processes (36). Two of these metalloproteinases, MMP2 and MMP9, have been reported to be associated with metastasis, and cancer cell invasion and migration into surrounding tissues are mediated by MMP2 and MMP9 (37,38). In addition, TIMP2, a specific inhibitor of MMP2, is associated with the activation status of MMP2 (16). Stat 3 is another important transcription factor that is involved in cell proliferation, survival, apoptosis and metastatic capability, which also has important roles in cancer aggressiveness, making it an attractive target for cancer therapy (39). Thus, the present study assessed whether these metastasis-associated proteins were associated with impaired metastasis in melanoma cells by western blotting. The results indicated that after treatment with pectolinarigenin, the metastatic ability of B16 cells was inhibited via MMP2- and MMP9-mediated pathways, and the metastatic ability of A375 was inhibited via the Stat3/MMP2/MMP9 pathway. In addition, previous studies have demonstrated that by interacting with the Stat3 pathway, pectolinarigenin can inhibit the proliferation, migration and invasion of osteosarcoma (40), breast cancer (39) and colorectal carcinoma (41) cells, which is in agreement with the results of the present study. In vitro and in vivo experiments were carried out in the three cited study, which demonstrated that pectolinarigenin suppressed metastasis. Pectolinarigenin induced apoptosis in colorectal and breast cancer cells by increasing the ratio of $\mathrm{Bax} / \mathrm{Bcl} 2$ and the expression of Cleaved Caspase-3 $(39,41)$, which was also demonstrated in the present study, and the ROS-mediated mitochondrial apoptotic pathway was involved in the pectolinarigenin induced apoptosis in melanoma cells. In addition, Zhang et al (40) have suggested that pectolinarigenin suppresses osteosarcoma growth and metastasis by SHP-1-mediated Stat3 signaling inhibition in vivo and in vitro, and pectolinarigenin significantly suppresses osteosarcoma cell proliferation, induces apoptosis and reduces the level of STAT3 downstream proteins cyclin D1, Survivin, Bcl-2, B-cell lymphoma extra-large and myeloid cell leukemia 1 . The anti-melanoma effect of pectolinarigenin in vivo, and the underlying mechanisms, need to be investigated in future studies.

The results of the present study demonstrated that pectolinarigenin exhibited antitumor activity on melanoma cells, causing the inhibition of A375 and B16 cell viability, proliferation, invasion and migration, and the induction of apoptosis via the ROS-mitochondrial apoptotic pathway. As pectolinarigenin inhibits melanogenesis, it may be an effective approach for anti-melanogenesis therapies (10), and melanogenesis serves a key role in the regulation of cellular metabolism (11). Of note, based on the present results and on previous studies, pectolinarigenin may be offered as a new potential agent for melanoma treatment based on its ability to inhibit the cell proliferation, induce apoptosis and block migration and invasion. However, there are certain limitations to the present study. For example, in the wounding healing assay, the same method was used to create identical wounds in each well at $0 \mathrm{~h}$, and there were no differences between wells when observed under a microscope; thus, images were not captured at $0 \mathrm{~h}$, and the relative wound closure could not be calculated. However, after treatment for $48 \mathrm{~h}$, the scratch was observed and images of every well were captured under a microscope to count the cells that had migrated into the wound area. Regarding the content of experiments, the present study focused on the role of pectolinarigenin in melanoma cell proliferation, apoptosis, migration and invasion; this was a primary study on the anti-melanoma ability of pectolinarigenin, providing a research basis for its anti-melanoma activity and recognizing its anti-melanoma ability. The present study had some limitations, including that on in vitro studies were performed, without detecting changes in melanin production in pigmented melanoma cells. In addition, the activity of related enzymes, and related genes expression levels were not analyzed. In our future studies, in vivo experiments will be performed to validate the anti-melanoma effects of pectolinarigenin. These 
studies will involve exploring the effect of pectolinarigenin on tumorigenesis, malignancy and metastasis of melanoma, and tissue inflammation and histopathological changes in animal models to provide a scientific basis for its anti-melanoma activity.

Overall, the results of the present study demonstrated that pectolinarigenin significantly inhibited cell proliferation, migration and invasion and induced apoptosis in vitro via a ROS-mediated mitochondrial pathway and an MMP2 and MMP9-mediated pathway. These results suggested that pectolinarigenin may serve as a new agent for melanoma treatment.

\section{Acknowledgements}

The authors would like to thank the members of the Tinghong Ye Lab (State Key of Laboratory of Biotherapy and Cancer Center of West China Hospital, Sichuan University) for their technical assistance.

\section{Funding}

No funding was received.

\section{Availability of data and materials}

The datasets used and/or analyzed during the present study are available from the corresponding author on reasonable request.

\section{Authors' contributions}

YD and WY contributed to the conception and design of the experiments. LW, QZ, YL, SY and CG performed the experiments. XC made contributions to collection and analysis of data. FH and TY made substantial contributions to the conception and design of the study. All authors have read and approved the final manuscript.

\section{Ethics approval and consent to participate}

Not applicable.

\section{Patient consent for publication}

Not applicable.

\section{Competing interests}

The authors declare that they have no competing interests.

\section{References}

1. Bray F, Ferlay J, Soerjomataram I, Siegel RL, Torre LA and Jemal A: Global cancer statistics 2018: GLOBOCAN estimates of incidence and mortality worldwide for 36 cancers in 185 countries. CA Cancer J Clin 68: 394-424, 2018.

2. Siegel RL, Miller KD and Jemal A: Cancer statistics, 2018. CA Cancer J Clin 68: 7-30, 2018.

3. Zheng Y, Wang K, Wu Y, Chen Y, Chen X, Hu CW and Hu F: Pinocembrin induces ER stress mediated apoptosis and suppresses autophagy in melanoma cells. Cancer Lett 431: 31-42, 2018.

4. Xiong J, Wang Y, Gu Y, Xue Y, Dang L and Li Y: CDK5RAP1 targeting NF- $\mathrm{KB}$ signaling pathway in human malignant melanoma A375 cell apoptosis. Oncol Lett 15: 4767-4774, 2018.
5. Slominski A, Zmijewski MA and Pawelek J: L-tyrosine and L-dihydroxyphenylalanine as hormone-like regulators of melanocyte functions. Pigment Cell Melanoma Res 25: 14-27, 2012.

6. Slominski A, Tobin DJ, Shibahara S and Wortsman J: Melanin pigmentation in mammalian skin and its hormonal regulation. Physiol Rev 84: 1155-1228, 2004.

7. Prota G: Melanins, melanogenesis and melanocytes: Looking at their functional significance from the chemist's viewpoint. Pigment Cell Res 13: 283-293, 2000.

8. Meredith P and Sarna T: The physical and chemical properties of eumelanin. Pigment Cell Res 19: 572-594, 2006.

9. Sarna T: Properties and function of the ocular melanin-a photobiophysical view. J Photochem Photobiol B 12: 215-258, 1992.

10. Lee S, Lee DH, Kim JC, Um BH, Sung SH, Jeong LS, Kim YK and Kim SN et al: Pectolinarigenin, an aglycone of pectolinarin, has more potent inhibitory activities on melanogenesis than pectolinarin. Biochem Biophys Res Commun 493: 765-772, 2017.

11. Slominski A, Kim TK, Brożyna AA, Janjetovic Z, Brooks DLP, Schwab LP, Skobowiat C, Jóźwicki W and Seagroves TN: The role of melanogenesis in regulation of melanoma behavior: Melanogenesis leads to stimulation of HIF-1 $\alpha$ expression and HIF-dependent attendant pathways. Arch Biochem Biophys 563: 79-93, 2014.

12. Slominski A, Zbytek B and Slominski R: Inhibitors of melanogenesis increase toxicity of cyclophosphamide and lymphocytes against melanoma cells. Int J Cancer 124: 1470-1477, 2009.

13. Brożyna AA, Jozwicki W, Roszkowski K, Filipiak J and Slominski AT: Melanin content in melanoma metastases affects the outcome of radiotherapy. Oncotarget 7: 17844-17853, 2016.

14. Zhang K, Lei J, He Y, Yang X, Zhang Z, Hao D, Wang B and He B: A flavonoids compound inhibits osteoclast differentiation by attenuating RANKL induced NFATc-1/c-Fos induction. Int Immunopharmacol 61: 150-155, 2018.

15. Bonesi M, Tundis R, Deguin B, Loizzo MR, Menichini F, Tillequin $\mathrm{F}$ and Menichini F: In vitro biological evaluation of novel 7-O-dialkylaminoalkyl cytotoxic pectolinarigenin derivatives against a panel of human cancer cell lines. Bioorg Med Chem Lett 18: 5431-5434, 2008.

16. Deng Y, Li Y, Yang F, Zeng A, Yang S, Luo Y, Zhang Y, Xie Y, Ye T, Xia Y and Yin W: The extract from Punica granatum (pomegranate) peel induces apoptosis and impairs metastasis in prostate cancer cells. Biomed Pharmacother 93: 976-984, 2017.

17. Li Y, Yang F, Zheng W, Hu M, Wang J, Ma S, Deng Y, Luo Y, Ye T and Yin W: Punica granatum (pomegranate) leaves extract induces apoptosis through mitochondrial intrinsic pathway and inhibits migration and invasion in non-small cell lung cancer in vitro. Biomed Pharmacother 80: 227-235, 2016.

18. Tuong W, Cheng LS and Armstrong AW: Melanoma: Epidemiology, diagnosis, treatment, and outcomes. Dermatol Clin 30: 113-124, 2012.

19. Panth N, Manandhar B and Paudel KR: Anticancer activity of Punica granatum (pomegranate): A review. Phytother Res 31: 568-578, 2017.

20. Wang CZ, Calway TD, Wen XD, Smith J, Yu C, Wang Y, Mehendale SR and Yuan CS: Hydrophobic flavonoids from Scutellaria baicalensis induce colorectal cancer cell apoptosis through a mitochondrial-mediated pathway. Int J Oncol 42: 1018-1026, 2013

21. Elkady AI, Abu-Zinadah OA and Hussein RA: Crude flavonoid extract of the medicinal herb nigella sativa inhibits proliferation and induces apoptosis in breast cancer cells. J Biomater Tiss Eng 7: 1235-1249, 2017.

22. Xu F, Gao X and Pan H: Pectolinarigenin inhibits non-small cell lung cancer progression by regulating the PTEN/PI3K/AKT signaling pathway. Oncol Rep 40: 3458-3468, 2018.

23. Hanahan D and Weinberg RA: Hallmarks of cancer: The next generation. Cell 144: 646-674, 2011.

24. Rahman N, Dhadi SR, Deshpande A and Ramakrishna W: Rice callus suspension culture inhibits growth of cell lines of multiple cancer types and induces apoptosis in lung cancer cell line. BMC Complement Altern Med 16: 427, 2016.

25. Hunter AM, LaCasse EC and Korneluk RG: The inhibitors of apoptosis (IAPs) as cancer targets. Apoptosis 12: 1543-1568, 2007.

26. Autret A and Martin SJ: Emerging role for members of the Bcl-2 family in mitochondrial morphogenesis. Mol Cell 36: 355-363, 2009.

27. Namura S, Zhu JM, Fink K, Endres M, Srinivasan A, Tomaselli KJ, Yuan J and Moskowitz MA: Activation and cleavage of caspase-3 in apoptosis induced by experimental cerebral ischemia. J Neurosci 18: 3659-3668, 1998. 
28. Lu M, Kong Q, Xu X, Lu H, Lu Z, Yu W, Zuo B, Su J and Guo R: Pectolinarigenin-a flavonoid compound from cirsium japonicum with potential anti-proliferation activity in MCF-7 breast cancer cell. Tropical J Pharma Res 13: 225, 2014.

29. Guo L, Yin Z, Wen L, Xin J, Gao X and Zheng X: Flower extracts from Paeonia decomposita and Paeonia ostii inhibit melanin synthesis via cAMP-CREB-associated melanogenesis signaling pathways in murine B16 melanoma cells. J Food Biochem 43: e12777, 2019.

30. Liu-Smith F and Meyskens FL: Molecular mechanisms of flavonoids in melanin synthesis and the potential for the prevention and treatment of melanoma. Mol Nutr Food Res 60: 1264-1274, 2016.

31. Alfadda AA and Sallam RM: Reactive oxygen species in health and disease. J Biomed Biotechnol 2012: 936486, 2012.

32. Wang $\mathrm{J}$ and Yi J: Cancer cell killing via ROS: To increase or decrease, that is the question. Cancer Biol Ther 7: 1875-1884, 2008.

33. Yang SP, Zhang YG, Luo Y, Xu B, Yao Y, Deng Y, Yang F, Ye T, Wang G, Cheng Z, et al: Hinokiflavone induces apoptosis in melanoma cells through the ROS-mitochondrial apoptotic pathway and impairs cell migration and invasion. Biomed Pharmacother 103: 101-110, 2018.

34. Talmadge JE and Fidler IJ: AACR centennial series: The biology of cancer metastasis: Historical perspective. Cancer Res 70 5649-5669, 2010.

35. Fidler IJ: The pathogenesis of cancer metastasis: The 'seed and soil' hypothesis revisited. Nat Rev Cancer 3: 453-458, 2003.
36. Kamran MZ and Gude RP: Preclinical evaluation of the antimetastatic efficacy of pentoxifylline on A375 human melanoma cell line. Biomed Pharmacother 66: 617-626, 2012.

37. Fietz S, Einspanier R, Hoppner S, Hertsch B and Bondzio A: Determination of MMP-2 and -9 activities in synovial fluid of horses with osteoarthritic and arthritic joint diseases using gelatin zymography and immunocapture activity assays. Equine Vet J 40: 266-271, 2008

38. Si L, Yan X, Hao W, Ma X, Ren H, Ren B, Li D, Dong Z and Zheng Q: Licochalcone $\mathrm{D}$ induces apoptosis and inhibits migration and invasion in human melanoma A375 cells. Oncol Rep 39: 2160-2170, 2018.

39. Li Y, Gan C, Zhang Y, Yu Y, Fan C, Deng Y, Zhang Q, Yu X, Zhang Y, Wang L, et al: Inhibition of Stat 3 signaling pathway by natural product pectolinarigenin attenuates breast cancer metastasis. Front Pharmacol 10: 1195, 2019.

40. Zhang T, Li S, Li J, Yin F, Hua Y, Wang Z, Lin B, Wang H, Zou D, Zhou Z, et al: Natural product pectolinarigenin inhibits osteosarcoma growth and metastasis via SHP-1-mediated STAT3 signaling inhibition. Cell Death Dis 7: e2421, 2016.

41. Gan C, Li Y, Yu Y, Yu X, Liu H, Zhang Q, Yin W, Yu L and Ye T: Natural product pectolinarigenin exhibits potent anti-metastatic activity in colorectal carcinoma cells in vitro and in vivo. Bioorg Med Chem 27: 115089, 2019.

(7) $\Theta$ This work is licensed under a Creative Commons

EY NC ND Attribution-NonCommercial-NoDerivatives 4.0 International (CC BY-NC-ND 4.0) License. 